\title{
The influence of renewables and international trade on investment decisions in the grid of the future
}

\author{
S. Cole ${ }^{1}$, D. Van Hertem ${ }^{1}$, L. Meeus ${ }^{1}$ and R. Belmans ${ }^{1}$ \\ ${ }^{1}$ Katholieke Universiteit Leuven \\ Dept. Electrical Engineering (ESAT), Div. ELECTA \\ Kasteelpark Arenberg 10, 3001 Leuven-Heverlee, Belgium \\ E-mail: stijn.cole@esat.kuleuven.be, dirk.vanhertem@ieee.org, leonardo.meeus@esat.kuleuven.be,
} ronnie.belmans@esat.kuleuven.be

\begin{abstract}
The importance of new network investments is generally recognized. In order to make efficient investment decisions for the future transmission grid, factors such as the integration of renewables in the grid and international trade have to be taken into account. The increased international energy flows due to trade in a consumer environment which expects the reliability of supply to increase, or at least remain at its current level, makes it clear that investments to increase the scarcely available cross-border transfer capacities are needed. Building new transmission lines could alleviate this problem. However, this is often unacceptable due to social and political circumstances. The development of new transmission technologies looks promising in this respect. The unpredictable behaviour of renewables makes it hard to balance consumed and generated electric power. This creates excellent opportunities for energy storage. Although electrical energy storage always has been regarded as not economical, recent developments have provided some new opportunities. This paper gives an overview of existing and new technologies that will determine the future power system. Special attention is given to energy storage systems.
\end{abstract}

\section{Keywords}

Power transmission, power transmission lines, flexible AC transmission systems, HVDC, energy storage, SMES, capacitive energy storage.

\section{Introduction}

Before liberalization and subsequent unbundling, the electricity industry was organized as vertically integrated monopolies. A growing disaffection of vertically integrated monopolies, liberalization successes in other sectors and the desire to foster competition in power generation were the primary motivations for liberalization. The main objective of the liberalization of the electricity market in Europe is the creation of an internal electricity market. Because the electricity price is not the same in all countries, an opportunity for trading arises. However, national grids are connected because of security and stability reasons. The European network is not designed with international trade in mind. Trade is therefore limited by the scarcely available cross-border transfer capacity. In order to increase total welfare, it is necessary to relieve the bottlenecks by increasing cross-border transfer capacity [1].
Another new development is the increasing integration of intermittent renewable energy sources in the grid. The grid is currently not suited for a massive introduction of renewables [2]. Two problems arise. First, the location of generation plants can not be chosen because they depend on geological constraints. Unfortunately, suitable geological locations for renewable generation plants are far away from load centers, e.g. offshore windparks and large hydroprojects. New technologies can help to transport these massive amounts of energy over large distances with minimal losses. Secondly, the unpredictable behavior of renewables makes it even harder to balance consumed and generated electric power. This creates excellent opportunities for energy storage. The more renewables in the grid, the more storage should be provided, in order to ensure security of supply.

While it is clear that liberalization necessitates transmission capacity investments, liberalization does not create a favorable investment climate if not supported by adequate regulation. In a liberalized market, grid and generation investments are decoupled due to the unbundling. The result is that grid investments are done facing uncertain regulation decisions at the one hand and generation investments at the other. The current regulatory framework does not sufficiently encourage grid investments. This situation leads to underinvestment [3].

Current social and political trends exacerbate this situation. The situation is characterized by the well-known acronyms NIMBY (Not In My Backyard) and NIMTO (Not In My Term Of Office).

While there have been many papers written comparing specific technologies with respect to technical and/or economical aspects (e.g. [4],[5],[6]), few studies exist that draw other relevant aspects in the comparison as well [7]. Rising environmental concern, social and political issues make it clear that an assessment of these new transmission and energy storage technologies on a mere technoeconomical basis is no longer sufficient. This paper is not meant to be an exhaustive summary of all existing technologies. A more elaborate discussion on existing and new technologies can be found in [7], [8], [9]. This paper will first discuss existing, proven technologies. Next some new transmission and energy storage technologies will be discussed, taking into account techno-economical as well as political, social and environmental aspects. 


\section{Grid reinforcement}

\section{A. Existing technologies}

1) Overhead AC transmission lines

Overhead AC transmission is the standard technology for electric power transportation. Traditionally it was preferred over any other transmission technology, especially in rural areas. No other technology can compete with overhead AC transmission in terms of cost. Technically and economically, overhead AC transmission provides an advantageous solution. However, because of political, social and environmental factors overhead AC transmission is becoming less favourable. Conventional network reinforcement projects face ever tougher siting opposition. The permitting process takes several years (ranging from 3 to 15 years). In order to avoid protest from environmentalists and those who live along the planned trajectory, it is recommended to inform the public about all issues concerning the planning of the new transmission line. The visibility of overhead lines is high.

\section{2) Underground AC cables}

Underground AC cables do not suffer from the aforementioned problems. The permitting process takes less time and social and political resistance is less. These advantages come, however, at a cost. The capital cost of underground lines is 3 to 20 times higher (in $€ /$ MVA) than that of overhead lines. Especially at high voltages, the cost difference is significant. Although there is a drive towards invisibility of the grid, it is economically not interesting to underground the entire grid [10].

3) LCC HVDC

A High-Voltage direct current (HVDC) system converts electrical current from AC to DC at the transmitting end and from $\mathrm{DC}$ to $\mathrm{AC}$ at the receiving end. Conventional HVDC is based on line commutated converters using thyristors. It is a well-established technology and since its first commercial introduction in 1954 (Sweden) more than 50 projects have been completed. HVDC transmission is most advantageous for long distances, without intermediate taps, and high amounts of energy, considering investments and losses but also land use (fig. 1).

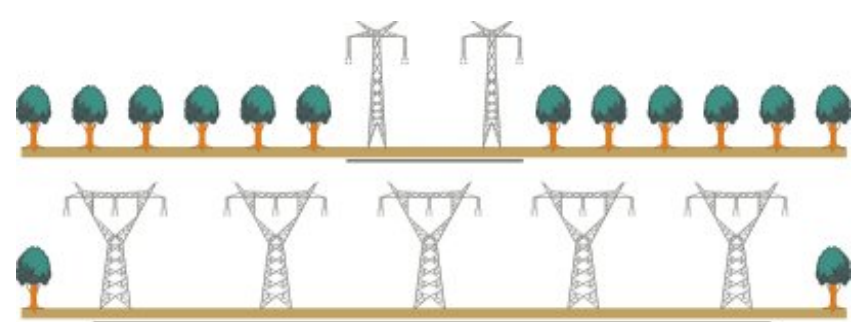

Fig. 1. Right -of-way requirement for 6,000 MW with two $\mathrm{DC}$ lines vs. five $500 \mathrm{kV}$ AC lines (ABB)

The technology allows power flow control, an interesting feature with respect to the discrepancies between contract paths and physical flows. The investment cost of HVDC converter stations is higher than the cost of AC substations. However, the cost of overhead lines or cables, right-of-way costs and operating and maintenance costs are lower with HVDC [11]. The longer the distance of the transmission, the more advantageous HVDC is, compared to HVAC transmission. In specific cases such as special requirements with regard to power flow control, limitations to short-circuit current or stabilizing needs HVDC has additional advantages over HVAC [12]. Figure 2 shows a converter station of a HVDC connection.

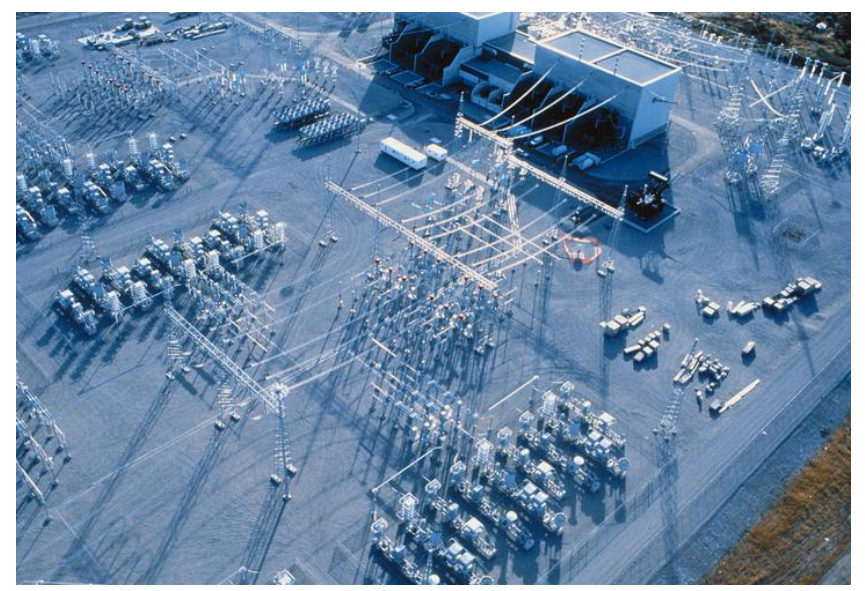

Fig. 2. LCC HVDC converter station (ABB)

\section{B. New technologies}

1) Extended use of existing technologies

Extended use of existing technologies can postpone the renewal of the grid. An example is temperature monitoring of underground cables, which allows operating closer to temperature limits.

2) New conductor materials

New conductors, which use composite materials, have an increased tensile strength and reduced weight. They also provide increased ampacity. When reconductoring an existing line with 
composite conductors, the ampacity increases without needing tower modifications. The first pilot projects are planned. Cost and limited experience are the major issues. Transmission capacity is increased with minimal environmental impact.

\section{3) HTS}

High temperature superconducting materials exist for a long time. Theoretically, superconducting materials could be used for almost all electric equipment in the power grid. HTS cables have no electrical resistance. The losses are therefore significantly lower compared to conventional cable. However, the cost to maintain operating temperature is very high. Moreover, the capital cost of the superconducting materials and the cryogenic equipment is also very high. Further $\mathrm{R} \& \mathrm{D}$ will drive the costs down, but large scale integration of superconducting technology in the grid is not to be expected on short term. From an ecological point of view, HTS cables are more interesting than oil-filled or gas insulated cables. HTS cables are environmentally friendly [13]. Figure 3 shows a single-core superconducting cable.

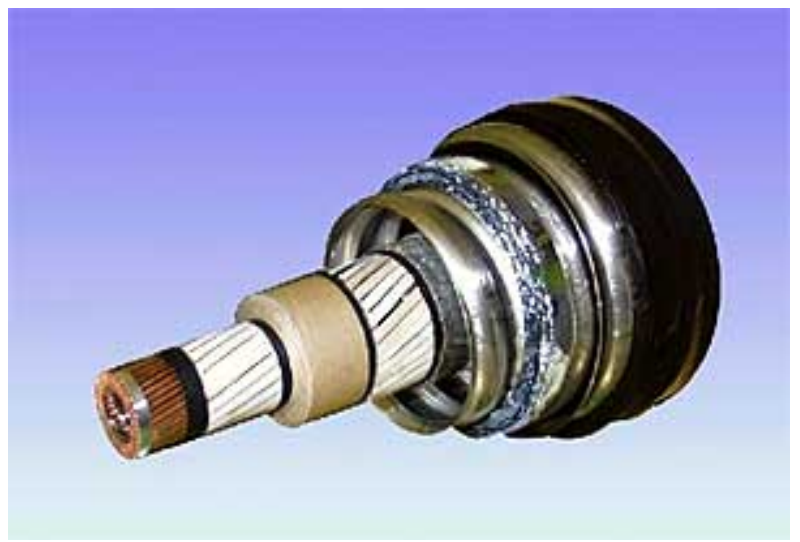

Fig. 3. Single-core HTS cable (Furukawa Electric Co., Ltd.)

4) VSC HVDC

A new development is DC transmission using voltage sourced converters (VSC). The use of devices with controlled turn-on and turn-off capability such as IGBTs offers interesting technical advantages. VSC HVDC provides full power control, both active and reactive. As such, VSC HVDC is perfectly suited for the connection of intermittent energy sources such as wind. Also black-start and energizing passive AC systems become possible. Also, commutation failures do not occur. VSC stations can eliminate flicker and reduce harmonics in the AC system. The better wave shape eliminates the need for large switchable harmonic filters. As a consequence the footprint of the converter stations is reduced. The losses in the voltage source converters are however higher because of more frequent switching operations and the higher voltage drop across the switching elements.

The overall cost of VSC converter stations is higher than for LCC stations, primarily due to technology costs. However, VSC HVDC transmission is an emerging technology. Technical breakthroughs and increased market introduction will push down the costs. This will bring about a change in the cost function advantageous to VSC HVDC technology.

VSC HVDC is an interesting alternative for high demand applications such as supplying additional energy to weak networks or connecting offshore wind parks. In [14] the use of HVDC for city infeed has been studied. While traditional HVDC is most cost-effective in the high power range, VSC HVDC is better for small power applications. VSC technology is not yet suited for bulk power transmission due to high costs associated with high voltage and current ratings. It has been developed up to $550 \mathrm{MW}$, but this limit increases fast.

\section{5) FACTS}

Flexible AC transmission systems or FACTS are devices which allow the flexible and dynamic control of power systems. These devices can be divided in three groups, dependent on their switching technology: mechanically switched (such as phase shifting transformers), thyristor switched or fast switched, using IGBTs. While some types of FACTS, such as the phase shifting transformer (PST) and the static var compensator (SVC) are already well known and used in power systems, new developments in power electronics and control have extended the application range of FACTS. Furthermore, intermittent renewable energy sources and increasing international power flows provide new applications for FACTS. The additional flexibility and controllability of FACTS allow to mitigate the problems associated with the unreliable of supply issues of renewables. SVCs and statcom devices are well suited to provide ancillary services (such as voltage control) to the grid and fault ride through capabilities which standard wind farms cannot provide [15] Furthermore, FACTS reduce oscillations in the grid, which is especially interesting when dealing with the stochastic behavior of renewables.

In a liberalized market, the added value of FACTS, and especially power flow controlling devices, is the ability to control flow paths and therefore the ability to resolve congestions and optimally utilizing available grid infrastructure [16], [17]. Although FACTS devices are currently quite expensive, it is expected that with a growing 
utilization and experience, prices will drop considerably.

\section{Conclusions}

While several technologies for grid reinforcement exist, there is certainly room for new developments. The changing situation in the electricity grid makes it clear that existing technology is not always suited to the needs of a modern grid. Newer technologies offer several advantages. VSC HVDC for instance, is particularly suited to the connection of wind parks. Also, with environment in mind, new technologies often score better.

\section{Electricity storage}

The production of electrical energy has to equal the demand, including transportation losses and auto consumption, at any time. Emerging renewable sources such as wind and solar power are neither controllable nor reliable [18]. Electricity supply becomes unpredictable and the need for expensive peaking generation arises. Furthermore, market volatility increases. Storage facilities can store energy at off-peak and inject energy at peak demand, allowing for less peaking generators.

Demand is not only not constant; it is also unpredictable, although to a lesser extent than production. As a result of the stochastic character, there is a need for hourly contracts in the spot market. A perfectly flat demand diagram would render hourly contracts superfluous. To flatten the demand diagram, storage plants can be used. A typical example is the reduced demand at night. At night, excess energy could be stored and during the day, when demand is peaking, released. Less production units would be needed, and they can operate at higher efficiency.

In this paper we evaluate energy storage systems on their balancing capabilities. However, there are secondary advantages, such as black-start capability.

Many different energy storage technologies are currently available. However, they all convert electricity to another form of energy.

\section{A. Existing technologies}

\section{1) Potential energy}

Electrical energy is used to pump water from a low reservoir to a higher one. The energy is stored as potential energy. Energy is released by turbining the water. This storage method is particularly suited for large scale energy storage. A serious disadvantage is the dependence of the design on specific geological formations. Mostly, these geological constraints cause difficult construction. There is rising public opposition because of environmental concerns: large pumped hydro installations can be disruptive to the ecosystem. These systems have a relative large time constant. The efficiency of such pumped hydro systems is about $70 \%$.

2) Compressed air

Because Compressed Air Energy Storage (CAES) plants can be very large, it is often seen as an alternative of pumped hydro storage. A compressor train compresses air, which is then stored in an underground cavern. When electric energy is needed, the air runs through an expander train, which drives an electric generator. The main drawback is the need for suitable geological structures, such as depleted salt caverns. Artificial caverns are not recommended because of the high cost involved. Efficiency and time constant are comparable to pumped hydro.

\section{3) Chemical energy}

A Battery Energy Storage (BES) system stores energy by using an electrochemical reaction. They can be found in many sizes and power ratings. From a technical point of view, several disadvantages exist. Maintenance requirements are high. Batteries have a limited lifetime and have to be replaced periodically. Batteries are very sensitive to heat: service life can be reduced considerably if operated above rated temperature. It is true that new types of batteries do not suffer from one or more of these drawbacks as much, but investment costs are higher.

Although batteries are often used in equipment to protect installations against power quality problems (e.g. UPS installations), this is not the case for transmission systems.

There are also environmental drawbacks linked to the use of batteries. Batteries contain toxic materials that can weigh hard on the environment. Special care must be taken when disposing of batteries.

\section{4) Kinetic energy}

A flywheel is a mass spinning around an axis. Flywheels store energy mechanically in the form of kinetic energy. Kinetic energy increases proportionally to mass and quadratically to speed. It is therefore more interesting to use low density, high tensile strength materials, which can spin extremely fast, than high-density materials. Efficiency of flywheel energy storage is very high. Friction can be significantly reduced by installation in a sealed vacuum chamber and by magnetic suspension. Flywheels typically have a long lifetime and high energy density. With respect to the environment, Flywheel Energy Storage (FES) systems are less potentially damaging than for instance BES systems. The charge/discharge rate is limited only by the motor/generator and can therefore be very fast; 
several charge and discharge cycles within a few minutes are possible. Being mechanical devices, flywheels require quite a lot of maintenance. Flywheels have a fairly low specific energy and the cost is too high to compete effectively with batteries for any application above the 10 minutes range.

\section{B. New technologies}

\section{1) SMES}

Superconducting Magnetic Energy Storage (SMES) is another application of HTS materials. A SMES device stores electric energy in the magnetic field of a superconducting coil. Currently, the application of SMES devices is limited to a few niche markets, especially in the power quality sector. An example is the use of a Dynamic Voltage Restorer (DVR) with integrated SMES for voltage mitigation in the semiconductor industry, where even the shortest voltage dip can be extremely costly. After only a few bridged power disturbances, the installation cost of a SMES is already recovered.

Theoretically, SMES systems could be used for all utility-side applications of energy storage. According to [19], they can be used to smooth fast-changing loads, even at distribution level. Already in the early 1970s R\&D work on largescale SMES, suitable for load leveling, has been started. Large-scale systems cause additional problems; e.g. the long coil lengths and the enormous electromechanical forces that require underground imbedding in rock [20], [21]. The most significant medium-scale SMES project is a $500 \mathrm{kWh}$ energy storage facility in Anchorage, Alaska. It is used as spinning reserve. It can dispatch $30 \mathrm{MW}$ for one minute, which will provide sufficient time to ramp up hydro capacity [22]. Large and medium-scale SMES systems are, however, exceptional. At present, there are very few utility-level applications of SMES. An example is the use of SMES in combination with flexible AC transmission systems such as Statcom or with FACTS devices such as the statcom or SSSC. It is not unimaginable that this situation could change due to increased experience and technological breakthroughs on diverse fields. However, today only small-scale SMES systems are economical efficient. This is reflected in the R\&D efforts that are almost solely focused on small-scale SMES systems in applications that benefit the most from the specific characteristics of SMES systems, notably fast response. Examples are oscillation damping, flicker diminishing, and so on.
2) Supercapacitors

Another method of storing electrical energy directly is by using supercapacitors (or ultracapacitors). Supercapacitors store electrical energy in the electric field between two electrodes by applying DC voltage. The operating principle of supercapacitors is that of everyday capacitors. The technology is enhanced by using modern materials. These new materials have higher dielectric constants, thus providing much higher energy storage capacity. While conventional capacitors have high power and low energy, supercapacitors have high power as well as high energy. The back-up time is generally limited to a few seconds at most. Supercapacitors have a number of distinctive advantages over batteries. Supercapacitors have a very fast charge and discharge rate, making them suitable to follow fast power fluctuations. Also, because of this fast discharge rate, supercapacitors are safe. The cycle life is virtually infinite and no maintenance is required. Furthermore, supercapacitors are environmentally friendly. Cost however is much higher compared to conventional batteries. Supercapacitors can advantageously replace batteries in some applications. Another possibility is to combine supercapacitors and batteries in one application. The cycling-duty of the batteries can be reduced which increases their lifetime. The combination of batteries and supercapacitors is well suited to provide power to loads that require pulsed and variable energy consumption, with reasonably large energy.

As supercapacitors are a fairly young technology, a lot of enhancements are provided by new technical developments. For instance materials technology enhances surface area and ionic electrolytes which both augment capacity.

Although supercapacitors clearly have numerous applications, for instance in combination with batteries in UPSs, telecommunications and in vehicles, they are not suitable for utility-side energy storage at first sight. Apart from the combination with Statcom or SSSC, there are not a lot of utility-level applications.

3) Hydrogen

Hydrogen is an energy carrier; it must be produced by using energy from other sources. Converting energy to hydrogen and back is not cheap. The conversion equipment is expensive and the process has high energy consumption. The roundtrip efficiency is considerably lower than that of competing technologies. Hydrogen itself is not pollutant. When hydrogen would be produced by for instance excess wind energy, it provides emission free energy. It is therefore very well regarded by environmentalists. Hydrogen is the most abundant element in the universe. On earth, 
we can find it as a component of water, which is virtually unlimited. Hydrogen has a high mass energy density. For storage, however, volumetric energy density is a more relevant parameter. Volumetric energy density is very low, which means that a lot of space is required to store it. Two methods are used to increase volumetric energy density. The first one is compression and is the most widely used. The second one is liquid hydrogen storage. The compression process and especially the liquefaction process (liquid hydrogen is cryogenic) require a lot of energy. The large penetration of wind energy can be facilitated by the integration of hydrogen systems [23]. In this system, a combination of off-shore wind energy coupled to a hydrogen system would allow a continuous, controllable and deterministic energy output of this composed system. At the current time these systems are not realistic because of technical and economical issues.

\section{Conclusions}

New energy storage technologies are promising. However, at present cost is a major issue. Continuous R\&D efforts are needed to make SMES and supercapacitors costeffective in a wide range of applications. For hydrogen, breakthroughs are needed to improve efficiency drastically and to make it competitive to established storage technologies.

\section{Comparisons}

Table I lists the advantages and drawbacks of some different transmission technologies. Existing technology scores well on economics and the fact that it is 'proven technology'. In general, newer technology is more environmentally friendly, and has distinct supplementary technological benefits [9].

Table II shows technical characteristics of various energy storage technologies. For bulk storage, only pumped hydro, CAES and batteries are technically as well as economically viable. Pumped hydro is only suited for large-scale energy storage applications. It is excellent for load leveling, providing black-start capability, and as operating reserve. Due to the limited prospect for new pumped hydro projects, there is certainly room for other large-scale energy storage systems.

CAES facilities become more and more interesting options when planning a large-scale energy storage facility. Due to geological constraints, the construction of new CAES, and particularly of new pumped hydro, is, however, limited. This will benefit BES systems, which have few geological requirements.

BES systems can be used for all energy storage applications. Battery energy storage systems are technically feasible for bulk energy storage but are less economic than pumped hydro and CAES. In the smallscale range, BES systems have to compete with newer technologies, such as SMES and supercapacitors. Many applications are cost-effective with battery storage technologies. The cost-effectiveness is enhanced if several applications are combined, for instance the combination of load leveling and power line stability. 
Table I: Advantages and disadvantages of alternatives for network reinforcement [9]

\begin{tabular}{|c|c|c|c|c|c|c|c|c|c|c|}
\hline & \multicolumn{3}{|c|}{ Social \& political } & \multicolumn{2}{|c|}{ Economical } & \multicolumn{5}{|c|}{ Technical } \\
\hline & 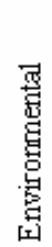 & 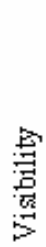 & $\begin{array}{l}\text { 骂 } \\
\text { 营 } \\
\text { 总 }\end{array}$ & 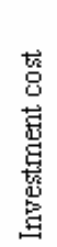 & $\begin{array}{l}\overrightarrow{\mathrm{g}} \\
\mathrm{S} \\
\text { 哭 } \\
\text { 总 } \\
\text { 号 }\end{array}$ & 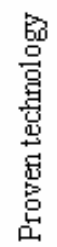 & 㟔 & 尺 & 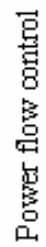 & 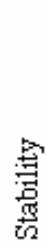 \\
\hline Classic overhead & - & -- & -- & + & - & ++ & + & - & - & $=$ \\
\hline $\begin{array}{l}\text { New conductor } \\
\text { types }\end{array}$ & $=$ & $=$ & + & + & - & -- & $?$ & - & - & $=$ \\
\hline Classic underground & - & + & - & - & + & + & ++ & - & - & $=$ \\
\hline HTS conductors & + & + & - & -- & ++ & -- & $?$ & - & - & $=$ \\
\hline PST & - & - & - & ++ & - & ++ & + & - & + & - \\
\hline $\begin{array}{l}\text { Thyristor based } \\
\text { FACTS }\end{array}$ & - & - & - & + & -- & - & - & + & + & + \\
\hline VSC basedFACTS & - & - & - & + & -- & -- & $?$ & ++ & + & ++ \\
\hline LCC HVDC & - & - & - & - & + & ++ & + & - & + & + \\
\hline VSC HVDC & - & - & - & -- & - & - & $?$ & ++ & + & ++ \\
\hline
\end{tabular}

Small-scale energy storage can be used on transmission and distribution level. Response time is much more crucial than size. BES, SMES, supercapacitors and flywheels are possible. The choice of an energy storage system depends on the requirements of the application. Generally, BES systems are the best choice, because no other system can compete in terms of cost. However, in applications where battery systems begin to reach their limits, other solutions like SMES, supercapacitors or flywheels become advantageous.

Table II: Technical characteristics of energy storage technologies

\begin{tabular}{|c|c|c|c|c|c|}
\hline & Power & $\begin{array}{c}\text { Back-up } \\
\text { time }\end{array}$ & $\begin{array}{c}\text { Response } \\
\text { time }\end{array}$ & Efficiency & Lifetime \\
\hline Pumped hydro & $200 \mathrm{MW} \rightarrow 2 \mathrm{GW}$ & hours & $\sim 12 \mathrm{~min}$ & $\sim 75 \%$ & $\sim 50 \mathrm{y}$ \\
\hline CAES & $25 \mathrm{MW} \rightarrow 2.7 \mathrm{GW}$ & hours & $\sim 12 \mathrm{~min}$ & $\sim 70 \%$ & $<50 \mathrm{y}$ \\
\hline Batteries & $\mathrm{KW} s \rightarrow 50 \mathrm{MW}$ & hours & seconds & $\sim 80 \%$ & $<10 \mathrm{y}$ \\
\hline Flywheels & $5 \mathrm{~kW} \rightarrow 3 \mathrm{MW}$ & mins & $\sim 12$ min & $<95 \%$ & $\sim 20 \mathrm{y}$ \\
\hline SMES & $10 \mathrm{~kW} \rightarrow 3 \mathrm{MW}$ & seconds & millisecs & $\sim 95 \%$ & $\sim 30 \mathrm{y}$ \\
\hline Supercapacitors & $<150 \mathrm{~kW}$ & seconds & millisecs & $<95 \%$ & $>10 \mathrm{y}$ \\
\hline
\end{tabular}




\section{Conclusions}

The importance of new network investments is generally recognized, especially to increase scarcely available crossborder transfer capacities. With the upcoming renewal in mind, the assessment of new technologies is important. While new technologies were not feasible in the past for techno-economic reasons, new developments such as social and political pressure for the drive towards an invisible and environmentally friendly grid can render viable their use. The same goes for energy storage technologies. Although large-scale energy storage is not widely used today, the uncertainty introduced by intermittent renewable energy sources can change this. The importance of energy storage is reflected in recent technical developments. Traditionally, electric energy was converted to another primary energy source for storage. Two relatively new technologies, SMES and supercapacitors, contradict the adage that electric energy is non-storable, by storing electric energy directly.

A detailed case-specific economic assessment is necessary to select the best technology.

\section{Acknowledgment}

The research performed at the KU Leuven is financially supported by the Belgian 'Fonds voor Wetenschappelijk Onderzoek (F.W.O.)-Vlaanderen'. Dirk Van Hertem is a doctoral research assistant of the F.W.O.-Vlaanderen.

\section{7. $\quad$ References}

[1] Directorate General Energy and Transport working paper strategy paper, 10th Florence forum, Mar. 2004. Available: http://europa.eu.int/comm/energy/

[2] European Wind Energy Association: "Integrating wind into Europe's grid network,” Wind Directions, Nov./Dec. 2005. Available: http://www.ewea.org

[3] L. Meeus, K. Purchala, R. Belmans: "Development of the internal electricity market in Europe,” Electricity Journal, Vol. 18, No. 6, pp. 25-35, July 2005. Available: http://www.esat.kuleuven.be/electa

[4] J. Mutale and G. Strbac, "Transmission network reinforcement versus FACTS: an economic assessment," IEEE Transactions on Power Systems, vol. 15, no. 1, pp. 961-967, Aug. 2000.

[5] K-S Tam, "A comparison of alternatives to enhance the utilization of transmission lines," Electric Power Systems Research, 41 (1997) pp. 133-140.

[6] T. Hayashi, M. Takasaki, "Transmission capability enhancement using power electronics technologies for the future power system in Japan," Electric Power Systems Research 44 (1) (1998) pp. 7-14.

[7] M. Rabinowitz, "Power systems of the future," part 1, pp. 516, part 2, pp.10-15, part 3, pp.21-24, part 4, pp. 4-9, IEEE Power Engineering Review, 2000.
[8] Cole S., Van Hertem D., Meeus L., Belmans R.: "Energy storage on production and transmission level: a SWOT analysis,” WSEAS Transactions on Power Systems, Vol.1, Issue 1, Jan. 2006; pp. 31-38. Available: http://www.esat.kuleuven.be/electa

[9] Cole S., Van Hertem D., Meeus L., Belmans R.: “Technical Developments for the Future Transmission Grid," International conference on future power systems, ISBN 9078205-01-6, Amsterdam, the Netherlands, Nov. 2005. Available: http://www.esat.kuleuven.be/electa

[10] EURELECTRIC, Statement on "Using underground Cable Technologies for High and Very High Voltage Transmission Links (150 kV and above) in Europe,” Mar. 2004, Available: http://www.eurelectric.org

[11] R. Rudervall, J.P. Charpentier and R. Sharma, "High Voltage Direct Current (HVDC) transmission systems technology review paper,” Available: http://www.worldbank.org.

[12] "VSC transmission," CIGRE, technical brochure no. 269, Apr. 2005.

[13] A. M. Wolsky, "Environment, safety, and health impact of HTS power equipment," IEEE Power Engineering Review, May 2000, pp. 12-15.

[14] P. Fischer de Toledo, "Feasibility of HVDC for city infeed," Lic. thesis. KTH, Stockholm, 2003, TRITA-ETS-2003-11.

[15] A. Kehrli, M. Ross, "Understanding grid integration issues at wind farms and solutions using voltage source converter FACTS technology,” Power Engineering Society General Meeting, 2003, IEEE, Volume 3, 13-17 Jul. 2003.

[16] C. Schaffner, G. Andersson: "Value of Controllable Devices in a Liberalized Electricity Market," 6th IEE International Conference on AC-DC Transmission, London, UK, 28th - 30th Nov. 2001.

[17] D. Van Hertem, J. Verboomen, R. Belmans, W. Kling: "Power flow control devices: An overview of their working principles and their application range," International conference on future power systems, ISBN 90-78205-01-6, Amsterdam, the Netherlands, 16-18 Nov., 2005; Available: http://www.esat.kuleuven.be/electa/publications/fulltexts/pub 1501.pdf

[18] P.B. Eriksen, T. Ackermann, H. Abildgaard, P. Smith, W. Winter, J.R. Garcia: "System operation with high wind penetration,” IEEE power \& energy magazine, Nov/Dec 2005.

[19] G. Yurek, J. Howe, and B. Kehrli, Recent advances in superconductivity for electric utility T\&D systems: laying the foundation for the electricity superhighway, Edison Electric Institute's transmission and distribution spring conference, 1999.

[20] A. Ter-Gazarian, Energy storage for power systems, IEE Energy Series 6, Peter Peregrinus Ltd., 1994.

[21] C.-S. Hsu, W.-J. Lee, "Superconducting magnetic energy storage for power system applications," IEEE Transactions on industry applications, Vol. 29, No. 5, Sep./Oct. 1992

[22] D. Larbalestier, R. D. Blaugher, R. E. Schwall, R. S. Sokolowski, M. Suenaga, and J. O. Willis, Power applications of superconductivity in Japan and Germany, WTEC panel report, http://www.wtec.org, 1997.

[23] A. Gonzalez, E. McKeogh, B.O. Gallachoir: "The role of hydrogen in high wind energy penetration electricity systems: The Irish case,“ Renewable Energy 29 (2003). 